\title{
COMBINING IDEAS IN CROWDSOURCED IDEA GENERATION
}

\author{
Kai WANG*, Hui WANG**, Yu TAO*** \\ Kean University College of Business and Public Management Union, New Jersey, United States \\ *e-mail: kaiwan@kean.edu \\ **e-mail: hwang4@stevens.edu \\ ***e-mail: ytao@stevens.edu
}

\begin{abstract}
Collecting ideas through crowdsourcing has become a common practice for companies to benefit from external ideas and innovate. It is desirable that crowd members build on each other's ideas to achieve synergy. This study proposes and verifies a new method for idea combination which can result in combined ideas that are both novel and useful. The domain-specific knowledge of crowd members does not influence the effectiveness of such idea combination. The new method can be used for collecting highly creative ideas from the crowd. The implications for future research are discussed.
\end{abstract}

Keywords: crowdsourcing, idea generation, idea combination, creativity, educational game, mechanical turk.

\section{Introduction}

In the pursuit of innovation, many companies have adopted the open innovation approach and try to benefit from external ideas and inventions (Cassiman and Valentini, 2016; Chesbrough, 2011; Przybylska, 2013). Collecting ideas through crowdsourcing has become a common practice in open innovation (Bayus, 2013; Howe, 2006; Poetz and Schreier, 2012). Crowdsourcing can be defined as outsourcing tasks to an undefined, large group of people through an open call (Howe, 2006). For example, some companies collect product or service ideas from consumers through online platforms (Bayus, 2013; Terwiesch and Ulrich, 2009; Toubia, 2006). Crowdsourcing enables many people to search for creative ideas in parallel (Afuah and Tucci, 2012; Michelucci and Dickinson, 2016; Ren, et al., 2014).

When a crowd has the knowledge and motivation, this crowdsourcing approach improves the chance of developing effective solutions to a company's problems (Afuah and Tucci, 2012; Poetz and Schreier, 2012). In many crowdsourced tasks, people work as individuals and compete with each other for a prize (Ebner, et al., 2009; Leimeister, et al., 2009). Alternatively, people's work can also be coordinated such that there is collaboration or integration (Kittur, et al., 2013; Michelucci and Dickinson, 2016; Ren, et al., 2014). The most famous crowd collaboration may be Wikipedia, an encyclopedia that anyone with
Internet access can edit. Wikipedia exemplifies the benefits of a well-designed mechanism for coordinating crowds' work.

Collaborative idea generation in a crowd has recently drawn much attention (Luo and Toubia, 2015; Siangliulue, et al., 2015). Since there can easily be hundreds or thousands of members in a crowd, organizing crowd collaboration in ideation is different from organizing group brainstorming. A simple approach is to show every crowd member some peers' good ideas that can be served as examples and stimuli (Luo and Toubia, 2015; Wang, et al., 2013). Many online platforms such as quirky.com, allourideas.org, and OpenIDEO.com (Siangliulue, et al., 2015) allow such kind of idea sharing and inspiration. Seeing others' ideas might help people come up with ideas that they would not have thought of otherwise (Garfield, et al., 2001; Nijstad and Stroebe, 2006; Siangliulue, et al., 2015). However, seeing others' ideas might also constrain thinking to similar ideas (Jansson and Smith, 1991; Smith, et al., 1993; Sio, et al., 2015). It is often argued that combining dissimilar ideas is an effective way to generate creative ideas (Chan and Schunn, 2015; Osborn, 1953). However, idea combination has its own pitfalls. First, two randomly selected ideas might not be compatible to be combined. Second, a combined idea is not necessarily a better idea (Chan and Schunn, 2015; Fleming, 2001). To address these two issues, this study 
designs a novel idea combination approach to generate high-quality, creative ideas from the crowd.

A first batch of ideas was collected from the first crowd and evaluated with regard to novelty and usefulness. Then the three most novel ideas and the three most useful ideas were simultaneously presented to the second crowd (distinct from the first crowd), who were asked to combine some elements from the novel ideas and the useful ideas. The purpose of idea combination is to have the crowd build on previous high quality ideas by achieving a balance between novelty and usefulness.

This study shows the effectiveness of idea combination method via a user study that involves Amazon Mechanical Turk workers to develop an online privacy education game prototype. As previous studies have shown that personal differences can moderate the effect of interventions to improve creativity (Althuizen and Wierenga 2014; Luo and Toubia 2015), this study also investigates the impact of crowd members' domain-specific knowledge on the effectiveness of idea combination in the user study.

\section{Background}

Because crowdsourcing has the potential to tap into the intellectual ability of a large number of people, it has attracted much research attention. Afuah and Tucci (2012) theorized that crowdsourcing innovation is particularly useful when:

1) the focal problem is easy to describe and can be broken down to relatively independent components;

2) when solutions lie out of a company's expertise;

3) required knowledge to solve the problem is pervasive in a crowd.

There are many empirical studies showing the benefits of crowdsourcing innovation, such as generating better product ideas than internal personnel (Poetz and Schreier, 2012; Schweitzer, et al., 2012), increasing the number of new products (Laursen, 2011), and resulting in revenue from new products (Lilien, et al., 2002; Nishikawa, et al., 2013).

Researchers have started to envision new ways of organizing crowds to achieve important results. For example, researchers propose to design sophisti- cated workflows and even eco-systems of crowd workers to solve complicated problems (Kittur, et al., 2013; Michelucci and Dickinson, 2016; Siangliulue et al., 2015). However, there is still limited effort for facilitating creative ideation of crowds. Specifically, as argued by some researchers (Majchrzak and Malhotra, 2013), crowdsourcing projects are rarely designed to facilitate idea combination, a common approach to promote creativity. Even though some crowdsourcing websites allow people to see and comment on peers' ideas, these websites usually don't guide people to combine ideas.

Idea combination is commonly considered a good approach for creative ideation (Chan and Schunn, 2015; Osborn, 1953). Being exposed to one idea might lead to fixation, that is, exploring only domains related to the idea (Jansson and Smith, 1991; Perttula and Sipila, 2007). In idea combination, however, people are exposed to multiple ideas and are less likely to fixate on one idea (Wang, et al., 2013). Combining the elements from two ideas may lead to new ideas with emergent properties (Kohn, et al., 2011). Therefore, it is clear that idea combination has the potential to improve idea creativity (Chan and Schunn, 2015; Osborn, 1953).

Some researchers propose to use human-based genetic algorithms to use idea combination in crowdsourcing (Ren, et al., 2014; $\mathrm{Yu}$ and Nickerson, 2011, 2013). Specifically, one crowd creates a first generation of ideas, and then the ideas are evaluated and ranked by another crowd. A third crowd creates a new generation of ideas by combining previous ideas. The selection of ideas to be combined can be biased towards highly evaluated ideas (Ren, et al., 2014; Yu and Nickerson, 2011, 2013). Repeating these steps can lead to multiple generations of ideas. However, the effect of such idea combination is not always significant.

In one study, the genetic algorithms led to better designs of chairs, but only after two iterations (i.e., the third generation ideas were better than the first generation ideas) ( $\mathrm{Yu}$ and Nickerson, 2011). In another experiment on designing graphical advertisement, combination-based genetic algorithms led to no improvement in design quality (Ren, et al., 2014). There are multiple reasons why idea combination does not always work. 
First, not every pair of ideas can be combined in meaningful ways. Second, a new idea generated by combination is not always a better idea. Creativity is commonly defined as being novel and useful (Hennessey and Amabile, 2010). A combined idea can have some novel elements but could seem bizarre and thus less practical or useful (Fleming, 2001; Ren et al., 2014). In addition, it has been argued that idea combination sometimes results in good ideas, and sometimes results in bad ideas. Therefore, on average, idea combination may not have a strong effect (Chan and Schunn, 2015; Girotra, et al., 2010).

In summary, idea combination has the potential to improve idea creativity. It is desirable to be able to tap into crowds' ideas and their combinatory possibilities. Yet, there is a lack of effective methods to use idea combination in crowdsourced ideation.

\section{$3 \quad$ Hypothesis development}

To achieve synergy among crowd members, specific methods for idea combination need to be developed. Typically, we want crowds to generate creative ideas. Since creativity is commonly conceptualized as having two dimensions: novelty and usefulness (Hennessey and Amabile, 2010), it is important to find an idea combination method that can result in ideas high in both novelty and usefulness.

We propose the following method for organizing idea combination in crowdsourcing. First, we collect an initial batch of ideas, called greenfield ideas, from one crowd. Greenfield here means that the ideas are generated without seeing others' ideas. These ideas are evaluated by the second crowd with regard to novelty and usefulness. Then, based on the evaluation, the three most novel ideas and the three most useful ideas are identified. Afterwards, another crowd, exposed to these six ideas, will be asked to combine some elements from both the novel ideas and the useful ideas. The ideas generated in this final step are called combined ideas.

We contend that this idea combination method is effective in that it leads to some ideas that are both highly novel and highly useful. First, although not every pair of ideas can be easily integrated, when a crowd member is exposed to six ideas, it is likely that meaningful idea combination can be achieved.
Second, some combined ideas will be highly novel due to elements coming from highly novel ideas (Berg, 2014). In addition, when people read different ideas, these ideas will activate different knowledge in mind (Nijstad and Stroebe 2006). In trying to combine distinct ideas, people need to make further associations or analogies to connect different knowledge activated. The extended associations and new analogies will most likely improve the idea novelty (Berg, 2014; Ren, et al., 2014). Third, since three of the candidate ideas to be combined are highly useful, the combined ideas tend to be useful because they are built on elements from highly useful ideas. Therefore, combining novel ideas and useful ideas may lead to ideas that are both novel and useful. Similarly, Berg (2014) argues that combining a commonly used concept and a new concept can lead to ideas that balance novelty and usefulness.

An important related notion is that both broad exploration and deep exploration can improve creativity (Rietzschel, et al., 2007). Broad exploration can be defined as searching different categories of ideas (Althuizen and Wierenga, 2014). Deep exploration is defined as searching within a specific semantic category beyond obvious ideas (Rietzschel, et al., 2007). Consistent with this notion of deep and broad exploration, a study on scientific publications shows that highly impactful publications use both combinations within a specific scientific domain and combinations across domains (Uzzi, et al., 2013). Applying the notion to a crowdsourcing context, when being exposed to unusual ideas, people may be led to broadly explore into different categories of ideas. When being exposed to useful ideas, people may be led to explore common categories but beyond the obvious ideas. If people are asked to combine highly novel ideas and highly useful ideas, they are likely to conduct both broad exploration and deep exploration. Consequently, they tend to generate highly creative ideas.

In summary, combining novel and useful ideas has the potential to result in ideas that are both novel and useful, that is, creative. However, there is no guarantee that all combined ideas will be more creative than greenfield ideas. Not all ideas can be combined in meaningful ways and not every crowd member is skillful in such combinations. 
Therefore, such positive potential may not be clear in average ideas, but only in the most creative ideas. In other words, the best combined ideas should be more creative than the best greenfield ideas. For example, if we have one hundred combined ideas and one hundred greenfield ideas, the top thirty creative combined ideas should be more creative than the counterpart in greenfield ideas.

H1. The most creative combined ideas are more creative than the most creative greenfield ideas.

Researchers have found that personal differences moderate the impact of methods for improving creative idea generation. For example, it was found that example solutions improve creativity for people with lower creative ability, not people with high creative ability (Althuizen and Wierenga, 2014). Luo and Toubia (2015) argue that domain-specific knowledge can moderate the effect of using peers' ideas as stimuli. They contend that while experts have structured domain knowledge and think in abstract ways, novices think in a more concrete way with less structured domain knowledge.

Consequently, showing peers' ideas as concrete idea examples fits better with cognitive structures of novices. Seeing peers' ideas can also lead to cognitive fixation: people may fixate on the knowledge represented in stimulus ideas and limit their exploration of solution space. They further argue that fixation is more likely to occur when people have greater knowledge and the stimuli are more familiar to them.

Consequently, people with more domain knowledge tend to fixate more and suffer more from the negative impact of fixation. The researchers conclude that showing peers' ideas benefits novices more than experts. On the other hand, responsiveness to stimuli is positively related to the similarity of stimuli to one's present cognitive state (Coskun, et al., 2000). When people have more domain knowledge, they are more likely to understand and be responsive to ideas in the domain. Furthermore, to be able to integrate distinct ideas effectively, people need high levels of domain knowledge. Berg (2014) argues that to combine concepts that are not obviously related, people often need to use analogical thinking, trying to identify the structural similarity and potential connections between concepts and their associations.
This process apparently can benefit from high level of domain knowledge. Chan and Schunn (2015) show that combining distant ideas does not necessarily lead to better solutions. However, better solutions are likely to emerge by building on those combinations and explore deeper with more iterations. We contend that people with high level of domain knowledge are more likely to work on idea combination and think deeper with further elaboration. Therefore, we propose the following hypothesis.

We propose that people with more domain-specific knowledge can benefit more from idea combination in our method. In other words, if idea combination increases creativity, the degree of such an increase should be higher for people with more domain knowledge.

H2. Crowd members' domain knowledge moderates the effect of idea combination such that people with high level of domain knowledge benefit more from idea combination.

\section{$4 \quad$ Methods}

The creative task used in the study is related to our project that develops a simple online game prototype to educate the game players on online privacy. The game listed a number of social media posts that can potentially lead to privacy concerns, for example, a post showing the address of one's new house and when the house will be unoccupied. Using a multiple choice question format, the players were asked to identify privacy issues and ways to fix the problems. The webpage for the game is:

\section{http://web.stevens.edu/depet/html/main_menu.html}

The game had been equipped with the content (i.e., social media posts). But there was a lack of game rules and reward strategies. Therefore, we employed US-based workers on Amazon Mechanical Turk for the generation of creative ideas of game rules and reward strategies.

We generated a crowdsourcing task on Amazon Mechanical Turk to collect the crowd's ideas. Specifically, the workers were instructed to play the game and then asked to generate one idea about game rules and reward strategies so that people would be motivated to play. 
To obtain greenfield ideas, we collected 100 responses from 100 workers. In these 100 responses, we removed eight responses that are not ideas (such as negative comments on the game). The remaining 92 ideas were evaluated on idea novelty and idea usefulness, both on the 7-point Likert scale with 7 being most novel or useful. Usefulness is defined as "the degree to which an idea is feasible and effective" and novelty is defined as "the degree to which an idea is not only rare but also ingenious, imaginative or surprising" (Dean et al. 2006). In this context, an idea is effective if it describes game rules and reward strategies that are appealing and motivating for game players, and most importantly, make the game an effective tool for online privacy education.

Since the game was designed to educate the general public, the general public is the target audience of the game and should be able to evaluate ideas for game rules. Therefore, we believe that crowd workers are arguably qualified to evaluate the game ideas. Each greenfield idea was evaluated on the two dimensions of novelty and usefulness by twenty crowd workers from Amazon Mechanical Turk. This is aligned with the finding that it takes twenty crowd evaluations to reach reliable measurement of idea quality (Riedl, et al., 2013). To encourage serious consideration in the idea evaluation, the workers were instructed to explain the reasoning behind ratings. The twenty scores in evaluation were averaged to obtain idea ratings. Based on idea ratings, the three most novel ideas (as idea group A) and the three most useful ideas (as idea group B) were identified. One idea was in both group A and group B. This idea was kept in group A but removed from group B. The fourth most useful idea was used to replace this idea in group B. Another 100 crowd workers (distinct from the previous 100 workers) were instructed to generate one idea on the same creative task as mentioned before. In the instruction, there was a link to a webpage listing idea group A and idea group B. The workers were asked to combine some idea elements from group $\mathrm{A}$ and some elements from group B.

After removing six non-idea responses, we collected 94 combined ideas. These combined ideas were further evaluated, using the exact same method as before. Idea creativity is calculated as the sum of novelty and usefulness. Since creativity is usually defined as being both novel and useful, it is a common practice to calculate creativity scores as the sum or average of novelty and usefulness scores (Althuizen and Wierenga, 2014; Burroughs, et al., 2011; Massetti, 1996). All the idea generation tasks had a payment of $\$ 0.5$. To improve motivation, the workers were promised a $\$ 20$ bonus if their ideas were adopted. All the idea evaluation tasks had a payment of $\$ 0.05$. The crowd workers who generated ideas are 35.6 year old on average $(\mathrm{SD}=11.3)$ with $58 \%$ being female.

The domain knowledge of the participants who generated ideas was measured using a 7-item scale, developed to assess domain-specific customer knowledge (the general public is the "customer" of the game) (Luo and Toubia, 2015; Mitchell and Dacin, 1996). Because the ideas are related to computer games, the domain is set as computer games. The scores are from 1 to 5 , with 5 being most knowledgeable. Example items include "I am very familiar with computer games." and "I read articles related to computer games all the time".

\section{$5 \quad$ Results}

We measured the novelty and usefulness of all ideas. Intraclass correlation coefficients show good levels of agreement among raters (ICC $=0.70$ for both novelty and usefulness). The measurement of domain knowledge, which contains 7 items, also has a high level of reliability (Cronbach's alpha 0.869). Idea novelty and usefulness show a positive correlation $(\mathrm{r}=0.625, \mathrm{n}=186, \mathrm{p}<0.001)$. In both the greenfield ideas and the combined ideas, top 30 ideas were identified by finding the 30 ideas with the highest creativity ratings. Table 1 provides the summary of these data.

From Table 1, we can see that novelty, usefulness and creativity of all ideas do not differ significantly between the greenfield ideas and the combined ideas. Comparing the top 30 ideas in the two idea groups, although usefulness does not differ significantly, the top 30 combined ideas score significantly higher in novelty and creativity than the top 30 greenfield ideas. These results support hypothesis H1. 
To test hypothesis $\mathrm{H} 2$, we used the following equation for linear regression:

$$
y=\beta_{0}+\beta_{1} \times x_{1}+\beta_{2} \times x_{2}+\beta_{3} \times x_{1} \times x_{2}+\varepsilon
$$

with $\mathrm{y}$ being idea creativity, $\mathrm{x}_{1}$ being domain knowledge of the participant, $\mathrm{x}_{2}$ being idea combination $(0$ or 1 , representing greenfield or combined ideas, respectively), $\varepsilon$ being the error term.
The product of $\mathrm{x}_{1}$ and $\mathrm{x}_{2}$ stands for the interaction of the two variables. If the proposed moderation effect exists, we should find significant interaction effect. Table 2 represents the results of the regression. There is no significant interaction effect between domain knowledge and idea combination.

Table 1. Idea Creativity Ratings

\begin{tabular}{|l|c|c|l|}
\hline \multicolumn{1}{|c|}{ Variable } & $\begin{array}{c}\text { Greenfield Ideas } \\
(\text { Mean } \pm \text { SD })\end{array}$ & $\begin{array}{c}\text { Combined Ideas } \\
(\text { Mean } \pm \text { SD })\end{array}$ & \multicolumn{1}{|c|}{ T-test } \\
\hline Novelty of all ideas & $4.75 \pm 0.61$ & $4.81 \pm 0.73$ & $\begin{array}{l}\mathrm{t}(180)=0.552 \\
\mathrm{p}=0.582\end{array}$ \\
\hline Usefulness of all ideas & $5.12 \pm 0.57$ & $5.21 \pm 0.62$ & $\begin{array}{l}\mathrm{t}(183)=0.922 \\
\mathrm{p}=0.358\end{array}$ \\
\hline Creativity of all ideas & $9.88 \pm 1.06$ & $10.01 \pm 1.23$ & $\begin{array}{l}\mathrm{t}(181)=0.807 \\
\mathrm{p}=0.421\end{array}$ \\
\hline Novelty of top 30 ideas & $5.28 \pm 0.35$ & $5.52 \pm 0.35$ & $\begin{array}{l}\mathrm{t}(58)=2.697 \\
\mathrm{p}=0.009\end{array}$ \\
\hline Usefulness of top 30 ideas & $5.64 \pm 0.31$ & $5.67 \pm 0.29$ & $\begin{array}{l}\mathrm{t}(58)=0.409 \\
\mathrm{p}=0.684\end{array}$ \\
\hline Creativity of top 30 ideas & $10.92 \pm 0.43$ & $11.19 \pm 0.42$ & $\begin{array}{l}\mathrm{t}(58)=2.50 \\
\mathrm{p}=0.015\end{array}$ \\
\hline
\end{tabular}

Table 2. Results of the Linear Regression

\begin{tabular}{|l|c|c|}
\hline \multicolumn{1}{|c|}{ Parameter } & Coefficient & Standard Error \\
\hline Intercept & $9.239^{*}$ & 0.533 \\
\hline Domain Knowledge & 0.186 & 0.152 \\
\hline Combination & 0.771 & 0.738 \\
\hline Domain knowledge X Combination & -0.186 & 0.205 \\
\hline
\end{tabular}

*Significant at .05

We ran similar regressions using idea novelty and idea usefulness as dependent variables and observed similar results: no significant interaction effect can be found. In addition to regressions, we also looked into the effect of idea combination on high and low knowledge participants. Specifically, we identified groups of participants with high or low level of domain knowledge (scoring at least one standard deviation above or below average). Based on t-tests (data not shown), idea combination did not significantly influence either high knowledge participants or low knowledge participants. Therefore, we find no support for hypothesis $\mathrm{H} 2$.

\section{Discussion}

This research tries to establish a simple approach for improving crowd idea generation and identify the role of domain knowledge in it. Previous studies often show that idea combination in crowdsourcing does not lead to better ideas (Chan and Schunn, 2015; Ren, et al., 2014), despite the popular notion that combining ideas is an effective way to improve creativity. 
In our study, even though our idea combination method did not improve average idea creativity, the most creative combined ideas were clearly more creative than the most creative greenfield ideas. In practice, people usually care much more about the best ideas that a crowd generates, rather than average idea quality. As predicted in hypothesis $\mathrm{H} 1$, when crowd members were asked to combine elements from highly novel ideas and highly useful ideas, their best ideas were more creative than the best greenfield ideas. This positive result indicates that we can use this simple idea combination method to achieve more creative outcome than otherwise.

Combining highly novel ideas and highly useful ideas tends to achieve a balance between novelty and usefulness and lead to highly creative ideas. In addition, highly novel and highly useful ideas, by the very nature, are often dissimilar. Therefore, people are required to think deeply to combine dissimilar ideas. In addition, novel examples tend to promote broad exploration of the solution space, while useful examples tend to promote deep exploration (Althuizen and Wierenga, 2014). The combination of these two types of ideas can potentially facilitate both types of exploration and benefit creativity (Althuizen and Wierenga, 2014; Schilling and Green, 2011; Uzzi, et al., 2013).

The data analysis also shows that the top 30 combined ideas are higher in novelty but not in usefulness, compared to the top 30 greenfield ideas. This is consistent with the view that idea combination tends to benefit novelty but not usefulness (Fleming, 2001). In fact, Fleming (2001) argues that novel combination leads to poorer usefulness on average, even though it creases the variability in usefulness. However, in our study, idea combination did not reduce average idea usefulness: this is probably because the combined ideas have elements from highly useful idea examples.

The regression results (Table 2) show that there is no significant main effect of either idea combination or domain knowledge. This is consistent with the study by Luo and Toubia (2015), where they also show no main effect of domain knowledge or exposure to stimulus ideas. Furthermore, the data suggests that there is no interaction effect between domain knowledge and idea combination, which is in conflict with our hypothesis $\mathrm{H} 2$.

The hypothesis $\mathrm{H} 2$ proposes that people with high levels of domain knowledge would benefit more from idea combination. It is possible that this positive effect is counteracted by the following two factors. First, people with more domain knowledge might think in more abstract ways and benefit less from concrete idea examples (Luo and Toubia, 2015). Second, there could be a ceiling effect in idea evaluation, that is, the tendency that people are reluctant to give extremely high evaluations. Consequently, detecting an improvement on idea quality when the idea quality of greenfield ideas is already good can be difficult. More research is needed to identify the exact reasons.

In the practice of crowdsourcing creative task, this study suggests that using the simple idea combination approach can lead to ideas of high creativity. We mentioned before that there are many websites that solicit ideas from the crowd, such as quirky.com, allourideas.org, and OpenIDEO.com. In these websites, it may be beneficial to:

1) identify two idea groups, that is, the most novel ideas and the most useful ideas from previous participants;

2) list them on the homepage;

3) encourage people to combine some idea elements from both idea groups.

This simple technique may increase the creativity of the best ideas.

This study also has some implications for future research. We confirm that combined ideas, on average, are not necessarily more creative than ideas generated from scratch. However, certain methods can be developed to improve the best ideas generated. Other methods for finding candidates for idea combination can be investigated or combined with our approach, for example, using crowd approaches or computational approaches to filter out similar ideas (Siangliulue, et al., 2015).

Detailed guidance on idea combination might be integrated with our approach to further improve crowdsourcing creative tasks. For example, using step-by-step instructions of analogy (Knoll and Horton, 2011) or other creativity techniques (Couger, 
et al., 1993; Summers and White, 1976; Wang, 2014) might work. Developing all these approaches can help improve synergy among crowd members and achieve remarkably creative outcome.

\section{Conclusion}

We introduced a simple approach to finding candidates for idea combination in crowdsourced creative tasks and showed that it can increase the creativity of best ideas generated. In our experiment, the domain knowledge has no main effect on idea creativity, and surprisingly, no interaction effect with idea com-bination. This new approach can be used to enhance collective idea generation in crowdsourcing. It also suggests some future research topics aiming at creative collaboration among crowd members.

\section{$8 \quad$ References}

[1] Afuah, A., Tucci, C.L., 2012. Crowdsourcing as a Solution to Distant Search. Academy of Management Review, 37(3), pp.355-375.

[2] Althuizen, N., and Wierenga, B., 2014. Supporting Creative Problem Solving with a Case-based Reasoning System. Journal of Management Information Systems, 31(1), pp.309-340.

[3] Bayus, Barry L., 2013. Crowdsourcing New Product Ideas Over Time: An Analysis of the Dell IdeaStorm Community. Management Science, 59(1), pp.226-244.

[4] Berg, J.M., 2014. The Primal Mark: How the Beginning Shapes the End in the Development of Creative Ideas. Organizational Behavior and Human Decision Processes, 125(1), pp.1-17.

[5] Burroughs, J.E., Dahl, D.W., Moreau, C.P., Chattopadhyay, A., and Gorn, G.J., 2011. Facilitating and Rewarding Creativity During New Product Development. Journal of Marketing, 75(4), pp.53-67.

[6] Cassiman, B., and Valentini, G., 2016. Open Innovation: Are Inbound and Outbound knowLedge Flows Really Complementary? Strategic Management Journal, 37(6), pp.1034-1046.

[7] Chan, J., and Schunn, C.D., 2015. The Importance of Iteration in Creative Conceptual Combination. Cognition 145, pp.104-115.
[8] Chesbrough, H.W., 2011. Bringing Open Innovation to Services. MIT Sloan Management Review, 52(2), pp.85-90.

[9] Couger, J.D., Higgins, L.F., and McIntyre, S.C., 1993. (Un)structured Creativity in Information Systems Organizations. MIS Quarterly 17(4), pp.375-394.

[10] Dean, D.L., Hender, J.M., Rodgers, T.L., and Santanen, E., 2006. Identifying Good Ideas: Constructs and Scales for Idea Evaluation. Journal of Association for Information Systems, 7(10), pp.646-699.

[11] Dugosh, K.L., and Paulus, P.B., 2005. Cognitive and Social Comparison Processes in Brainstorming. Journal of experimental social psychology, 41(3), pp.313-320.

[12] Ebner, W., Leimeister, J.M., and Krcmar, H., 2009. Community Engineering for Innovations: The Ideas Competition as a Method to Nurture a Virtual Community for Innovations. $R \& D$ Management, 39(4), pp.342-356.

[13] Fleming, L., 2001. Recombinant Uncertainty in Technological Search. Management science, 47(1), pp.117-132.

[14] Garfield, M.J., Taylor, N.J., Dennis, A.R., and Satzinger, J.W., 2001. Research Report: Modifying Paradigms - Individual Differences, Creativity Techniques, and Exposure to Ideas in Group Idea Generation. Information Systems Research, 12(3), pp.322-333.

[15] Girotra, K., Terwiesch, C., and Ulrich, K.T., 2010. Idea Generation and the Quality of the Best Idea. Management Science, 56(4), pp.591605.

[16] Hennessey, B.A., and Amabile, T.M., 2010. Creativity. Annual Review of Psychology, 61, pp.569-598.

[17] Howe, J., 2006. The Rise of Crowdsourcing. Wired, 14(6), pp.1-4.

[18] Jansson, D., and Smith, S., 1991. Design Fixation. Design Studies, 12(1), pp.3-11.

[19] Kittur, A., Nickerson, J.V., Bernstein, M., Gerber, E., Shaw, A., Zimmerman, J., Lease, M., and Horton, J., 2013. The Future of Crowd Work. Proceedings of the 2013 Conference on Computer Supported Cooperative Work, pp.1301-1318. 
[20] Knoll, S.W., and Horton, G., 2011. Changing the Perspective: Using a Cognitive Model to Improve Think Lets for Ideation. Journal of Management Information Systems, 28(1), pp.85-114.

[21] Kohn, N.W., Paulus, P.B., and Choi, Y., 2011. Building on the Ideas of Others: An Examination of the Idea Combination Process. Journal of Experimental Social Psychology, 47(3), pp.554561.

[22] Laursen, K., 2011. User-producer Interaction as a Driver of Innovation: Costs and Advantages in an Open Innovation Model. Science and Public Policy, 38, pp.713-723.

[23] Leimeister, J.M., Huber, M., Bretschneider, U., and Krcmar, H., 2009. Leveraging Crowdsourcing: Activation-Supporting Components for IT-Based Ideas Competition. Journal of Management Information Systems, 26(1), pp.197224.

[24] Lilien, G., Morrison, P.D., Searls, K., Sonnack, M. and von Hippel E., 2002. Performance Assessment of the Lead User Generation Process for New Product Development. Management Science, 48, pp.1042-1059.

[25] Luo, L., and Toubia, O., 2015. Improving Online Idea Generation Platforms and Customizing the Task Structure on the Basis of Consumers' Domain-Specific Knowledge. Journal of Marketing, 79(5), pp.100-114.

[26] Majchrzak, A., and Malhotra, A., 2013. Towards an Information Systems Perspective and Research Agenda on Crowdsourcing for Innovation. The Journal of Strategic Information Systems, 22(4), pp.257-268.

[27] Massetti, B., 1996. An Empirical Examination of the Value of Creativity Support Systems on Idea Generation. MIS quarterly, 20(1), pp.83-97.

[28] Michelucci, P., and Dickinson, J.L., 2016. The Power of Crowds. Science, 35(1), pp.32-33.

[29] Mitchell, A., and Dacin, P.A., 1996. The Assessment of Alternative Measures of Consumer Expertise. Journal of Consumer Research, 23(3), pp.219-239.

[30] Nijstad, B.A., and Stroebe, W., 2006. How the Group Affects the Mind: A Cognitive Model of Idea Generation in Groups. Personality and Social Psychology Review, 10(3), pp.186-213.
[31] Nishikawa, H., M. Schreier, and S. Ogawa., 2013. User-generated Versus DesignerGenerated Products: A Performance Assessment at Muji. International Journal of Research in Marketing, 30, pp.160-167.

[32] Osborn, A.F., 1953. Applied Imagination, New York: Scribners.

[33] Perttula, M., and Sipilä, P., 2007. The Idea Exposure Paradigm in Design Idea Generation. Journal of Engineering Design, 18(1), pp.93102.

[34] Poetz, M.K., and Schreier, M., 2012. The Value of Crowdsourcing: Can Users Really compete with Professionals in Generating New Product Ideas? Journal of Product Innovation Management, 29(2), pp.245-256.

[35] Przybylska, N., 2013. Crowdsourcing as a Method of Obtaining Information. Foundations of Management, 5(1), pp.43-51.

[36] Riedl, C., Blohm, I., Leimeister, J.M., and Krcmar, H., 2013. The Effect of Rating Scales on Decision Quality and User Attitudes in Online Innovation Communities. International Journal of Electronic Commerce, 17(3), pp.7-36.

[37] Rietzschel, E.F., Nijstad, B.A., and Stroebe, W., 2007. Relative Accessibility of Domain Knowledge and Creativity: The Effects of Knowledge Activation on the Quantity and Originality of Generated Ideas. Journal of Experimental Social Psychology, 43(6), pp.933-46.

[38] Ren, J., Nickerson, J.V., Mason, W., Sakamoto, Y., and Graber, B., 2014. Increasing the Crowd's Capacity to Create: How Alternative Generation Affects the Diversity, Relevance and Effectiveness of Generated Ads. Decision Support Systems, 65, pp. 28-39.

[39] Santanen, E. L., Briggs, R.O., De Vreede, G., 2004. Causal Relationships in Creative Problem Solving: Comparing Facilitation Interventions for Ideation. Journal of Management Information Systems, 20(4), pp.167-198.

[40] Schilling, M.A., and Green, E., 2011. Recombinant Search and Breakthrough Idea Generation: An Analysis of High Impact Papers in the Social Sciences. Research Policy, 40(10), pp.13211331. 
[41] Schweitzer, F.M., Buchinger, W., Gassmann, O., and Obrist., M., 2012. Crowdsourcing Leveraging Innovation through Online Idea Competitions. Research-Technology Management, 55, pp.32-38.

[42] Siangliulue, P., Arnold, K.C., Gajos, K.Z., and Dow, S.P., 2015. Toward Collaborative Ideation at Scale: Leveraging Ideas from Others to Generate More Creative and Diverse Ideas. Proceedings of the 18th ACM Conference on Computer Supported Cooperative Work and Social Computing, pp.937-945.

[43] Sio, U.N., Kotovsky, K., and Cagan, J., 2015. Fixation or Inspiration? A Meta-analytic Review of the Role of Examples on Design Processes. Design Studies, 39, pp.70-99.

[44] Smith, S.M., Ward, T.B., and Schumacher, J.S., 1993. Constraining Effects of Examples in a Creative Generation Task. Memory and Cognition, 21(6), pp.837-845.

[45] Summers, I., and White, D.E., 1976. Creativity Techniques: Toward Improvement of the Decision Process. Academy of management Review,1(2), pp.99-108.

[46] Terwiesch, C. and Ulrich, K.T., 2009. Innovation Tournaments: Creating and Selecting Ex- ceptional Opportunities, Boston: Harvard Business School Press.

[47] Toubia, O., 2006. Idea Generation, Creativity, and Incentives. Marketing Science, 25(5), pp.411-425.

[48] Uzzi, B., Mukherjee, S., Stringer, M., and Jones, B., 2013. Atypical Combinations and Scientific Impact. Science, 342(6157), pp.468-472.

[49] Wang, K., Nickerson, J.V., and Sakamoto, Y., 2013. Crowdsourced Idea Generation: The Effect of Exposure to an Original Idea. Proceedings of 2013 Americas Conference on Information Systems.

[50] Wang, K., 2014. Factors Influencing the Adoption and Effective Use of Creativity Techniques in Business Settings: An Exploratory Study. Engineering Management Journal, 26(4), pp.29-37.

[51] Yu, L., and Nickerson, J.V., 2011. Cooks or Cobblers? Crowd Creativity through Combination. Proceedings of Conference on Human Factors in Computing Systems, pp.1393-1402.

[52] Yu, L, and Nickerson, J.V., 2013. An InternetScale Idea Generation System. ACM Transactions of Interactive Intelligent Systems, 3(1), pp. 2:1-2:24. 